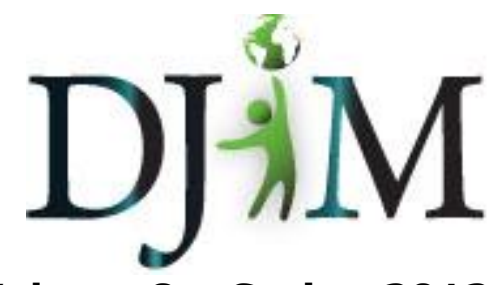

Volume 8 - Spring 2012 djim.management.dal.ca

\title{
The Breast vs. Bottle Battle: Infant Feeding Mis/Information
}

\begin{abstract}
That "breast is best" is a truism even infant formula manufacturers do not openly dispute, and the choice to breastfeed has increasingly become part of the measure of a good mother in modern Canadian society. Yet the information in support of breastfeeding's purported benefits is problematic, even as public discourse vilifies the alternative. This paper examines the issues surrounding infant feeding choices and the way in which information is utilized and manipulated by both sides of the emotionally charged breast versus bottle debate. While there are good reasons to support breastfeeding practices, the current state of our knowledge of its benefits does not justify the often strident tone and harsh judgment adopted by breastfeeding advocates.
\end{abstract}

\begin{abstract}
About the Author(s): Melissa Rothfus is a current student in Dalhousie's MLIS program with a long-standing interest in issues related to the establishment and communication of social norms and accepted behaviors. The research involved in this paper, written for the course INFO 5505 Information and Society, provided an exciting opportunity to return to several issues that interested her as an undergraduate at Macalester College.
\end{abstract}




\section{Introduction}

Mother's bodies are a battlefield, and the weapons are information. Information, subject to selection, manipulation, and interpretation, derived by scientists and endorsed by governments, is too often employed to create a circumstance where the choice to breast or bottle-feed an infant in the manifold complexities of family life is reduced to a judgment of good or bad, right or wrong. While certain benefits of breastfeeding to both infant and mother have been determined to exist, those findings and their value are not uncontested. The pressure to sort through this information and make correct choices is particularly high stakes in a social and cultural environment that sees, and blames, personal choices as the root cause of life's ills, from obesity to miscarriage to breast cancer (Knaak, 2010; Wolf, 2011; Yadlon, 1997). In this environment, trusted authorities in governments and health care systems have an obligation to provide sound policies and recommendations, but even these organizations and professionals can be bogged down by rhetoric, ideologies, and resentments. There is at present a need for research and analysis to determine what advantages to breastfeeding exist, the standard by which possible advantages will be determined, and how and to what extent breastfeeding can and should be promoted. These decisions should be made with both the impact on the infant's health and the health and dynamic of families in mind.

\section{From the Development of Viable Alternatives to Present Recommendations}

Current debates on breastfeeding stem from the development of viable substitutes for breast milk in the early twentieth century. In the 1920s, the development of infant formulas, prescribed by doctors and used under their supervision, took off in an environment that increasingly valued the authority of science and the submission of life choices to scientific measure, study, and knowledge. By the mid-twentieth century, bottle-feeding was the norm. Infants were subjected to scheduled feedings of fixed quantities. Their healthy development was measured by weight on the paediatrician's scale. At the same time, pregnancy and birth were fully medicalized, with general anaesthesia and surgical intervention common, and mothers and infants rooming separately in hospitals for days and nights at a time (Nathoo \& Ostry, 2009).

In response to this set of circumstances, La Leche League was born in suburban Chicago and made its way to Canada in the early 1960s. Arguing that breastfeeding was a "womanly art" that had been usurped by (male) physicians, La Leche League provided breastfeeding support for women unable to find it elsewhere (Nathoo \& Ostry, 2009). Though the group's perspective and messages were considered radical at the time because they opposed the medical establishment, in essence much of its philosophy was and is socially conservative and aimed at supporting married, heterosexual mothers who stay at home with their children (Blum, 1999; Nathoo \& Ostry, 2009; Wall, 2001). Social conservatives generally have supported this upswing in breastfeeding promotion against practices they see as threatening the root of the 
traditional family and its defined gender roles. Making for rather strange bedfellows, also in support have been feminists who find over-medicalization disempowering to women by usurping their bodily agency (Wall, 2001).

In the 1970s and 1980s, attitudes within the medical community shifted in favour of breastfeeding and it has joined in advocating breastfeeding over formula feeding, citing studies that suggest health benefits to both infant and mother (Nathoo \& Ostry, 2009). The World Health Organization (WHO) now recommends infants be breastfed exclusively for the first six months of life, and supplementing table foods for two years or more. These guidelines have been adopted by Health Canada (HC) (Health Canada, 2008).

Even manufacturers of formula are apparently in agreement that breast milk is best for babies. The website for Nestlé says of its Good Start formula, "Nothing else is breast milk. But for those who can't breastfeed, or for those who choose to supplement, one thing is clear: nothing else is Good Start $\AA^{\circledR}$ Probiotic - our closest formula to breast milk" ("Nestlé Good Start", 2008).

With such disparate groups in apparent agreement, the question of whether an infant should be breastfed might seem an uncomplicated one. Yet, though $89 \%$ of Canadian women initiate breastfeeding, only $24 \%$ meet $\mathrm{HC}$ and $\mathrm{WHO}$ guidelines to breastfeed exclusively for six months, suggesting that the way to sustain those initial efforts is eluding Canadian women (Statistics Canada, 2011; Weeks, 2010). Furthermore, a new backlash has arisen, primarily representing feminist voices which question the validity of the empirical foundation behind medical recommendations to breastfeed and criticize a policy of advocacy that shrouds ideology in scientific data.

At the heart of the backlash is that while a wide range of the health benefits to children are ascribed to breastfeeding by health authorities and breastfeeding advocates, including reduced risk of ear infections, asthma, gastrointestinal diseases, and greater IQ scores, among other benefits, the scientific backing behind all of these claims some consider weak (Wolf, 2011). Only breastfeeding's small benefit to the gastro-intestinal system meets the standards of proof to the strictest critics. Breastfed babies can expect to suffer one less bout of diarrhoea in their first year, compared to their bottle-fed peers (Rosin, 2009; Woolf, 2011). All other benefits are open to debate.

The new backlash does not represent advocacy of formula-feeding or denigration of breastfeeding or breast milk. At issue is the quality and implementation, some would say manipulation, of information that is used to persuade and promote the practice (Knaak, 2010). Debates surrounding breastfeeding and its merits demonstrate the lack of neutrality of information, and the power of information. Though attitudes and practices are changing, the lack of success in achieving breastfeeding rate goals has been shown not to be the result of a lack of persuasive information, but an incomplete information package, one that often does not 
sufficiently acknowledge the context in which it will be employed and interpreted (Heinig, 2009). The result is that amidst the barrage of data, statistics, anecdotes, policies, wisdom, and certainties, the information families need to make well-informed and clear-headed choices most appropriate to them is often lacking. Instead, mothers are compelled to adopt or justify their choices in an environment of bias and judgement.

\section{Infant Feeding Information Sources}

Information about infant feeding comes from a wide range of sources. A number of variables will determine how these rank in influence and perceived authority to shape attitudes and settle choices. For the purposes of this paper, it is sufficient to survey the sources and the nature of the information widely available in order to obtain a sense of the information environment in which parents make decisions about infant feeding.

Parenting books display different attitudes towards breastfeeding. The top-selling general baby care book on the Canadian Amazon and Chapters websites is William Sears' The Baby Book. Sears is a well-known proponent of attachment parenting, a style of parenting that advocates breastfeeding, baby-wearing, and co-sleeping among other practices as central not only to physical, but emotional child development. The two other most popular general baby care books on those websites are Canada's Baby Care Book and The Mother of All Baby Books: An All Canadian Guide to Your Baby's First Year, both of which take a more balanced approach to infant feeding.

For the present generation of women of childbearing age, their own mothers may not be a particularly helpful resource on breastfeeding issues because women of the previous generation overwhelmingly bottle-fed. While they cannot provide information on their own breastfeeding experiences, they can point to their own success with formula, which might be an appealing message for some women who otherwise feel bombarded and pressured by the pro-breastfeeding message (Andrew \& Harvey, 2011; Wallace, 2007).

Internet sources, magazines, and newspapers can present a variety of perspectives, some of which I will consider below. A popular Canadian parenting magazine is Today's Parent which advocates adherence to $\mathrm{HC}$ guidelines. An overwhelming number of websites are dedicated to some aspect of infant care. One of the most popular is the American BabyCenter.com, which has recently started new sites in other countries, including BabyCenter.ca. Both sites consistently were among the first listed in Google.ca searches for baby care and various aspects of it. A study by Rashley (2005) found that although the site provides a wealth of authoritative information in the form of articles by paediatricians and other experts on a broad range of issues pertaining to pregnancy, birth, and infant care, it also contains a subtle bias in favour of traditional gender roles, epitomized by married middle-class breastfeeding stay-athome moms. Articles, sometimes explicitly, tend to assume this is the position of the site's readers. This bias marginalizes women who do not meet that description. Discussion boards 
and reader responses to posted questions could sometimes be quite hostile towards these mothers. Yet Rashley also found the site's sponsorship by formula companies compromised its contents and suggested that women with breastfeeding problems were better served elsewhere. Certainly, websites abound to cater to almost every possible bias, but for a googling parent looking for general, trustworthy information, BabyCenter is a commonly consulted family of sites (2005).

Commercials, ads, and other marketing efforts on behalf of formula manufacturers also contribute to the information environment. As we shall see, though expectant mothers might not deliberately consult such a source, aggressive marketing ensures that the message as to how formula can benefit families is widely disseminated.

Another source, ostensibly neutral and therefore trustworthy, is the federal government, working in tandem with doctors, other health care professionals, and provincial governments to promote adherence to $\mathrm{HC}$ guidelines. These efforts include the production of posters, pamphlets, television commercials, and websites designed to inform Canadians of the advantages of breastfeeding, counter the marketing of formula, and alert the public to resources available to assist them, including those not part of the government. Breastfeeding Basics, a publication of the government of Nova Scotia and distributed to new mothers, includes La Leche League among services and programs available to assist (2009). It is the only body on the list not a part of the government, which might cause confusion as to its nature.

\section{The Rise and Fall (?) of Formula}

Times have changed since the heyday of formula feeding in the mid-twentieth century, and many of the medical interventions favoured at that time, including the promotion of formula, are largely considered excessive today. Even so, the sale of formula is big business; as we have seen above, $76 \%$ of Canadian women fall short of meeting WHO and $\mathrm{HC}$ breastfeeding goals (Statistics Canada, 2011; Weeks, 2010). This shortfall is often understood as the result of inadequate support to overcome the serious difficulties often experienced by new mothers in their attempts to breastfeed (Hoffman, 2000; Van de Geyn, 2010), but other factors, including the difficulty of sustaining breastfeeding after mothers return to work, discomfort with the notion of breastfeeding arising from the sexualization of breasts, a desire for more equitable division of child care within a couple, and a host of other purely personal reasons are possible explanations (Friedman, 2009; Stearns, 2009; Wolf, 2011).

Nonetheless, formula manufacturers have seen their profits jeopardized by current pushes to breastfeed and the concurrent scrutiny of the relationships between formula manufacturers and hospitals. Companies have long competed for exclusive contracts to provide formula samples to hospitals. As research shows mothers have tended to have brand loyalty to the formula they were given by hospitals, these contracts have been critical marketing tools 
(Nathoo \& Ostry, 2009). Hospitals are increasingly abandoning these contracts, however, in order to gain compliance with WHO guidelines designed to support breastfeeding (Nathoo \& Ostry, 2009). As a result, formula makers have changed their strategies, marketing directly to mothers and grafting themselves onto the message of breastfeeding advocates.

When hospitals pass out formula samples, they do two things to assist the formula manufacturer: they ensure that the product is on hand should the temptation to use it ever arise, and by virtue of their dual role as a centre of health authority and distributor of formula, they endorse the product with reassurances of its safety and benefits. Finding that they cannot continue to depend on the cooperation of hospitals to ensure their product is on hand, formula companies have sought to replace that tool in two ways. Websites, magazines, and maternity clothing stores provide customers with the opportunity to sign up for product giveaways that include formula samples and coupons in order to get the product into the homes of potential consumers. To replace the endorsement of hospitals, formula markets have coopted their message, seemingly supporting breastfeeding advocacy while offering their product as a complement to breast milk. In echoing the position of health officials, formula advertisers borrow their authority, and do not inspire the consumer to examine their claims critically.

But these advertising campaigns do more than repeat recommendations to breastfeed, they subtly add to them. While searching Factiva for articles on breastfeeding in Canadian newspapers, I came across an advertisement, disguised as an article, in the Montreal Gazette. Entitled "When feeding baby, breast is best," it contained much basic, general information about the intentions of many Canadian mothers to breastfeed and tips for how expectant mothers should prepare for the arrival of their babies. It was only when in the concluding paragraphs the author quoted a physician recommending a specific brand of formula - Nestlé Good Start - and extolling its unique qualities and benefits that I was alerted to the fact that I was reading an advertisement. Examining the ad once more with a critical eye, I saw how skilfully information about breastfeeding was manipulated. The advertisement cited an unspecified study that found the majority of women expect breastfeeding to be natural and easy. This is not saying that breastfeeding is natural and easy, but it does suggest the idea to the unwary reader. Since the shock of the difficulty common in initial breastfeeding attempts is believed to be an obstacle to sustained efforts (Hoffman, 2006; Van de Geyn, 2010), this ad does its part to ensure that the reader is unprepared to persevere when these difficulties occur to her. The ad then goes on to suggest supplies needed for breastfeeding moms: lanolin cream for sore nipples, ice packs for engorged breasts, and formula, just in case the need arises ("When feeding baby", 2010). While breastfeeding is made to sound easy, it is also made to sound frightening and painful, which makes the suggestion to ensure there is some formula on hand seem reasonable. 


\section{The Pro-Breastfeeding Message}

Often the message of breastfeeding promotion is a narrow, targeted one: "breast is best," sometimes expressed as a corollary, "formula is bad." Since a major part of infant care and its measure is infant feeding, the message then progresses to "bad mothers feed their babies formula." This message leaves very little room for mothers who would prefer not to breastfeed, who cannot for health reasons, or whose circumstances make it difficult or problematic. Even Nestlé, in its advertising for its Good Start formula quoted above, makes no room for these mothers when it explicitly targets its product "for those who can't breastfeed, or for those who choose to supplement..." ("Nestlé Good Start", 2008). Nestlé has not lost track of its bottom line here, but is nevertheless shying away from a direct conflict with the language of breastfeeding promotion.

The message that formula-feeding is deviant is widespread and explicit among breastfeeding advocates. Advocacy language that focuses on the risks of formula has become increasingly popular in response to the failure to achieve sustained breastfeeding rates to match the high rates of breastfeeding initiation (Heinig, 2009; Knaak, 2010). INFACT Canada, a breastfeeding advocacy group, has "14 Risks of Formula Feeding" at the top of its website's list of factsheets (“INFACT Canada Fact Sheets", n.d.).

The use of risk language is significant because it increases the intensity and judgement surrounding infant feeding decisions. Parents who choose to formula feed are seen as not only not doing what is best for their babies, but putting them at risk of compromised health. This is particularly troubling in a cultural environment of limited tolerance for risk and the expectation that mothers should be selfless moderators and managers of all risks to their children. Because of an understanding that formula-feeding mothers are not acting for their children's best interest, there is a widespread belief, sometimes internalized by the formula-feeder themselves, that they are not good mothers (Artis, 2009; Blum, 1999; Hoffman, 2000; Knaak, 2010; Kukla, 2006; Maxted, 2011; Wolf, 2011). That risk language is seen in a Toronto Star article from earlier this year. In a criticism of a proposed draft on infant feeding recommendations by Health Canada that including formula feeding as an acceptable, though not best, alternative, Kelly Matijcio, a lactation consultant was quoted saying:

We should be talking about the risks of artificial feeding and infant formula and treating those methods of feeding as a separate intervention that is only considered when medically indicated. Breastfeeding is the biggest single factor that can affect a baby's health. (Douglas, 2011, para. 9)

The definition of formula as a medical intervention only allowable under certain circumstances is an extreme one that makes formula feeding aberrant with no allowances for personal circumstances. Survivors of sexual abuse, who often find breastfeeding psychologically traumatizing (Kukla, 2006), as well as women whose need or desire to work outside the house 
does not facilitiate sustained breastfeeding, are villainized and marginalized by such a statement (Stearns, 2009; Wallace, 2007). This point of view is given voice not only by Ms. Matijcio to her clients, but broadcast to the Canadian population at large in this article that quotes her without dissent, criticism, or context. It contributes to a culture of harsh judgment and intolerance that spreads beyond the readership of the Toronto Star.

It is this kind of declaration that creates a difficult environment for mothers who formula feed, no matter what the reason. Demonstrating the persistance, and danger, of this message is a recent editorial in the Vancouver Sun, in which the author railed against the hostile atmosphere toward women who cannot or do not breastfeed. The author struggled to breastfeed but hesitated to try the alternative, "brainwashed by the [National Childbirth Trust] NCT and other hard-line members of the Breastapo, I almost believed it was better to starve my son than pollute him with formula" (Maxted, 2011, para. 7).

The attitudes described in these pieces have been in place for over a decade. A Today's Parent article title asked, "in our zeal to promote breastfeeding, have we turned our backs on the women who don't?" (Hoffman, 2000). The article cites a number of stories of women who cannot breastfeed and resort to formula in an environment that judges and shames them. One woman initially tried to hide the fact that she was using formula even from a public health nurse. The article's author declares in response, "We've worked so hard to make breastfeeding the norm that we seem to have created a social underclass of mothers who bottlefeed" (para.17). Yet all of the examples used in the article were of women who went to extremes in their efforts to nurse before giving up reluctantly, and the conclusions of the article were that more supports need to be in place for such women so that their efforts will be rewarded with the success they have earned. While sympathetic to women who have valiantly struggled to breastfeed despite physiological difficulties, other women who, for whatever reason, have simply chosen not to breastfeed are absent from the article, and absent from the extension of sympathy and support. The author's thesis is not that formula is an acceptable choice, but confirms that it is a shameful one by explicitly placing blame for the embarrassment and guilt the women described having suffered on medical professionals for not doing more to assist breastfeeding, instead of affirming that formula feeding is a legitimate alternative whose use ought not be condemned. Bottle-feeding women looking for support will not find it here, and a message that initially looks broader and more inclusive is revealed to be more narrow.

More recently, Brian Goldman, host of the CBC radio show, White Coat, Black Art addressed the topic of mothers who struggled with breastfeeding and received a deluge of stories of women who felt great pressure to breastfeed, even when extended efforts did not see success. One mother, whose infant was perpetually fussy, unsatisfied, and continued to lose weight went for four weeks before tests confirmed that she did not have an adequate milk supply and had been starving her son. During that time her struggle was supervised by public health nurses. Despite her baby's failure to thrive, which is measured through weight gain, formula had never been suggested to her, even as a supplement. The women who shared their stories 
"had been made to feel that failing to nurse their babies was tantamount to child abuse" (Wente, 2011, para.4).

What voice fathers should have, and what role they should play as caregivers when their partners breastfeed, are usually unaddressed in breastfeeding promotion. Yet, they are far from unaffected by infant-feeding decisions. The close bond that breastfeeding fosters between mother and infant sometimes comes at the expense of the father/infant attachment. Breastfeeding also fosters a dynamic in which mothers become the primary child caregivers in general, even when a more equitable division of labour is desired by both parents (Friedman, 2009; Rashley, 2005; Stearns, 2009). The time and energies of fathers deserve to be better appreciated in households where mothers struggle to fulfill all of their work and family responsibilities, yet there are relatively few resources to address how their contributions can be best utilized when mothers breastfeed (Friedman, 2009).

\section{The Problematic Support Behind the Advocacy}

Considering the widely shared beliefs of the benefits of breastfeeding and breast milk for infants, it is perhaps not surprising that there are widespread efforts to promote and support breastfeeding practices. This is especially so given that formula manufacturers have not been inactive in pursuing the largest possible portion of a limited market share. But the quality of the information available from all sources has begun to be questioned within the last few years, even while the notion that breast milk is the only acceptable food for infants has flourished. Many of the dissenting voices come from feminist academics critical of an agenda that promotes a practice for the benefit of infants without consideration of the possible negative impacts on mothers, or without consideration of mitigating circumstances in the mother's life.

One dissenting voice in popular media appeared in 2009, in an article in The Atlantic Monthly by Hanna Rosin entitled "The case against breastfeeding." The title was inflammatory, and not truly reflective of Rosin's thesis which was that the scientifically-backed benefits of breastfeeding are limited and thus the choice to breastfeed or not should truly be a free and open choice, done without shame, coercion, or judgement. The article lit a firestorm of controversy, with many knee-jerk reactions responding more to the title than the contents. The United States Committee on Breastfeeding urged its members to send a form letter in protest to The Atlantic Monthly, and 976 people from 49 states did so (Tiryakian, 2009). Many of these reactions, including the form letter just mentioned, did not address the question of limited medical evidence. Instead, they refocused the issue on the lack of support that adds to the difficulties of breastfeeding and called on Rosin to join in attacking the institutions, norms, and practices that contribute to those difficulties.

More recently, Joan B. Wolf's book, Is Breast Best? Taking on the Breastfeeding Experts in the New High Stakes of Motherhood has challenged received wisdom of the medical community (2011). Wolf examines the question of breastfeeding in its cultural context, including biases 
that inform scientific research. Among her conclusions is that the benefits of breast milk are framed in terms of risk that is not contextualized. For example, every time a child is loaded into a car, there comes risk of a possibly fatal accident, but that risk is tolerated in the broader context of life. However, medical studies framed in terms of risk are difficult to measure against other factors, and quickly become absolutes.

A further, more controversial criticism is that many of the studies measuring the benefit of breastfeeding are not scientifically sound. One frequent problem is a failure to control for confounding, or other variables that might influence an outcome. For example, breastfeeding rates are higher among well-educated, upper-middle-class families. Is the good health enjoyed by children in those families due to breast milk, or the other advantages at their disposal? Too often, that question is not addressed. Wolf's survey of medical literature found that the more tightly the studies controlled for other variables, the more equivocal the evidence to support breastfeeding becomes, except in the case of gastrointestinal infections, where proof of some benefit has been empirically established (Wolf, 2011). Michael Kramer, a professor of paediatrics at McGill University and a researcher who has designed some of the most respected breastfeeding research agrees that better evidence is needed to support many of the claims made by breastfeeding advocates. Nevertheless, Kramer expresses belief that further research will provide additional justification for breastfeeding advocacy, though having just admitted the slim basis on which current advocacy rests, one is left uncertain as to the foundation of this belief (Rumbelow, 2010).

The language with which medical research is communicated within the medical community and to the public also skews the information. One of the problems is the overwhelming quantity of information that is produced, which makes appreciating its finer points more difficult, especially for non-specialists. Wolf describes physicians and scientists relying on conventional wisdom, passed on and repeated without critical examination. For example, even when the authors of a study find no statistically significant advantage to breastfeeding, they repeat in their conclusions its established advantages, thereby perpetuating this conventional wisdom within medical literature. At the heart of this cycle is an inability to process and communicate the critical details amidst an overwhelming wealth of information:

The evolution of conventional wisdom about breastfeeding exemplifies what economists call "informational cascades," a process of information-diffusion in which an individual accepts the judgment of another person or critical mass of others largely because the costs of making his or her own evaluation in regard to time, money, or intellectual energy, are too steep (Wolf, 2011, p. 37).

This situation escalates when the information is exported from the scientific community into popular discourse, where the training and mindset to criticize established authorities are often lacking. Thus, statistically insignificant suggestions become scientific facts. 
Others before Wolf have challenged the extent of the health benefits claimed by breastfeeding advocates (Blum, 1999), but Wolf's extensive study and her conclusions are particularly important because they have received attention from the popular media. The Globe and Mail article that described the mothers featured on Brian Goldman's CBC show tied their struggles in with Wolf's thesis (Wente, 2011). In the UK, Helen Rumbelow wrote an article for The Times later republished in Significance that followed up on Wolf's conclusion with established medical authorities, including Michael Kramer. These are small, but hopefully significant steps towards more responsible reflection of the state of information surrounding the choice to breastfeed or not.

\section{Conclusions}

Breastfeeding advocates, convinced of the value and advantages of breastfeeding over formula feeding, have implemented strategies to provide women with the information they feel mothers need in order to make the choice to breastfeed. Television commercials, pamphlets, posters, magazine articles, and parenting websites have all been utilized to popularize the conclusion that breast is best. When rates of initiation or sustained breastfeeding have fallen short of expectations, the solution has largely been to put out more information, centred on the notion that mothers should be patient with the process of learning and fear the risks of using formula. The limited success of these information campaigns is an indication that the problem with the failures to sustain breastfeeding rates is not solely due to a lack of information. Studies have shown that the benefits purported by advocates are widely known, even among mothers who chose not to breastfeed at all (Heinig, 2009).

While Canada has guaranteed maternity leave and provincial laws that largely protect the rights of nursing mothers to breastfeed in public or find accommodation in their workplaces, problems remain. Poor families, for example, may find that employment insurance payments for maternity leave that come to $45 \%$ of usual earnings are simply insufficient. In other cases, cultural associations, especially the sexualization of female breasts, make breastfeeding in front of others uncomfortable and leave mothers vulnerable to lascivious or hostile gazes (Kukla, 2006). Many women find breast pumps uncomfortable and inadequate for maintaining their milk supplies, which makes it difficult or impossible for working mothers to continue to breastfeed even when employers provide time and a comfortable space for pumping. Some women, especially survivors of sexual abuse or assault but not limited to them, do not like to breastfeed and do not want to do it. Better study and utilization of the information as to why some women avoid breastfeeding and others do not meet WHO and $\mathrm{HC}$ guidelines might help improve those numbers, though they are often not likely to be problems that a little more information in another public relations campaign can fix.

A great service could be done to all Canadian parents by acknowledging just what the stakes

are in the breast versus bottle contest. While some health benefits of breastfeeding are supported by scientific findings, the medical support behind the more grandiose claims of 
breast milk benefits is weak or non-existent. This is not to say that greater benefits, currently unproven, may not be found to exist with later study, but the present state of medical knowledge does not justify the sometimes inflammatory message that serves to instil guilt and shame in mothers and families who are doing their best to cope with the challenges of infant rearing in the complexity of real life.

Those charged with the responsibility of supplying the public with information on the health benefits of breastfeeding need to take into consideration the incomplete state of knowledge regarding breastfeeding's purported benefits. The attitude found in medical literature (Wolf, 2011) that suggests women should be advised to go ahead and breastfeed even if the medical foundation for that advice is weak assumes that message does no harm. For those people who for any possible personal or physical reason cannot or desire not to breastfeed in an environment where there is tremendous pressure to do so, that message does do harm.

Those concerned with the well-being of families, particularly provincial and federal governments and associated agencies, should be concerned not only with the quality and accuracy of the information they provide, but the manner and tone in which it is provided. While a relationship between hospitals and formula manufacturers is inappropriate, the relationship between hospitals and health care workers with an ideologically driven organization like La Leche League is also worthy of reconsideration. The group, run by passionate volunteers with a number of resources at their disposal, can provide much emotional as well as practical support for new nursing mothers. For the current generation of women whose mothers likely did not breastfeed, such an organization can provide tremendous help and alleviate some of the burden from the health care system. Yet, at the very least, clear information about the nature of the organization and its agenda, and how it is distinct and different from a department within the health care system should be plain to mothers who are referred to their services and support.

Coming up against the marketing tactics of formula manufacturers, it is not difficult to understand why the voices of breastfeeding advocates can be so strident. In the words of Kramer, a leading expert on breastfeeding research, "The trouble is that the breastfeeding lobby is at war with the formula milk industry... and neither side is being very scientific... when it comes to a crusade, people are not very rational" (Rumbelow, 2010, p. 170). Among the causalities of this war are the subtle bits of information, the equivocations, the details, the contexts that turn a black-and-white issue into shades of grey. With them, too often, fall comfort, peace of mind, and the ability of loving, responsible women to be "good mothers." 


\section{References}

Andrew, N. \& Harvey, K.N. (2011). Infant feeding choices: Experience, self-identity and lifestyle. Maternal and Child Nutrition, 7(1), 48-60. doi:10.1111/j.17408709.2009.00222.x/pdf

Artis, J. (2009). Breastfeed at your own risk. Contexts, 8(4), 28-34. doi:10.1525/ctx.2009.8.4.28

Blum, L. (1999). At the breast: Ideologies of breastfeeding and motherhood in the contemporary United States. Boston: Beacon Press.

Breastfeeding Battles: Why has mother's milk become so controversial? (1996). Today's Parent, 12(9), 50. Retrieved from http://www.todaysparent.com

Canada's baby care book: A complete guide from birth to 12-months old. (n.d.). Retrieved December 7, 2011, from amazon: http://www.amazon.ca/Canadas-Baby-Care-Book-12Months/dp/077880156X/ref=sr 1 1?ie=UTF8\&qid=1323353478\&sr=8-1

Douglas, A. (2011, January 31). Breastfeeding groups petition Health Canada. Toronto Star. Retrieved from Lexisnexis database.

Friedman, M. (2009). For whom is breast best? Journal of the Association for Research on Mothering, 11(1), 26-35. Retrieved from http://pi.library.yorku.ca/ojs index.php/jarm/article/ viewFile/22506/20986

Health Canada. (2008, January 7). Exclusive Breastfeeding Duration - 2004 Health Canada Recommendation. (Cat. No.: H44-73/2004E-HTML). Retrieved from http://www.hcsc.gc.ca/fn-an/nutrition/infant-nourisson/excl bf dur-dur am excl-eng.php

Heinig, M. (2009). Are there risks to using risk-based messages to promote breastfeeding? Journal of Human Lactation, 25(1), 7-8. doi:10.1177/0890334408330192

Hoffman, J. (2000). Lacto-intolerance: In our zeal to promote breast feeding, have we turned our backs on the women who don't? Today's Parent, 17(11), 54. Retrieved from http://www.todaysparent.com

Hoffman, J. (2006). Nursing confidential. Today's Parent, 23(10), 95-96,98,100,102. Retrieved from http://www.todaysparent.com

INFACT Canada Fact Sheets. (n.d.). Retrieved from INFACT Canada: http://infactcanada.ca/FactSheets.htm 
Knaak, S. (2010, August). Contextualising risk, constructing choice: Breastfeeding and good mothering in risk society. Health, Risk \& Society, 12(4), 345-355.

doi:10.1080/13698571003789666

Kukla, R. (2006, February). Ethics and ideology in breastfeeding advocacy campaigns. Hypatia, 21(1), 157-180. doi:10.1111/j.1527-2001.2006.tb00970.x

Maxted, A. (2011, May 16). Breastfeeding: Protect us from the Breastapo. Vancouver Sun. Retrieved from Factiva database.

Nathoo, T. \& Ostry, A.S. (2009). The one best way? Breastfeeding history, politics, and policy in Canada. Waterloo: Wilfred Laurier University Press.

Nestlé Good Start Probiotic. (2008). Retrieved from Nesté-Baby.ca: http://www.nestlebaby.ca/en/products/formula/starter/goodstart probiotic.htm

Nova Scota Health Promotion and Protection. (2009). Breastfeeding basics. Halifax: Communications Nova Scotia.

Nova Scotia Health Promotion and Protection. (n.d.). Retrieved from http://www.first6weeks.ca/

Rashley, L. H. (2005). "Work it out with your wife": Gendered expectations and parenting rhetoric online. NWSA Journal, 17(1), 58-92. Retrieved from http://muse.jhu.edu.ezproxy.library.dal.ca/journals/nwsa journal/v017/17.1rashley.html

Rosin, H. (2009, April). "The case against breastfeeding. The Atlantic Magazine. 303(3), 64-70. Retrieved from http://www.theatlantic.com

Rumbelow, H. (2010). Breast is best? Exposing the myths of breastfeeding. Significance (7), 168-170. doi:10.1111/j.1740-9713.2010.00453.x

Statistics Canada. (2011, April 29). Breastfeeding, 2009. (Catalog No. 82-625-X) Retrieved from http://www.statcan.gc.ca/pub/82-625-x/2010002/article/11269-eng.htm

Stearns, C. (2009, Fall/Winter). The work of breastfeeding. Women's Studies Quarterly, 37(3/4), 63-80. Retrieved from http://www.jstor.org/stable/27740575

Tiryakian, E. C. (2009, June). Letters to the Editor. 303(5), 12-16. Retrieved from http://www.theatlantic.com

Van de Geyn, L. (2010, August). What nobody tells you. Today's Parent, 27(8), 60-62, 64, 66. Retrieved from http://www.todaysparent.com

Wall, G. (2001, August). Moral constructions of motherhood in breastfeeding discourse. Gender and Society, 15(4), 592-610. Retrieved from http://www.jstor.org/stable/3081924 
Wallace, L. \&. (2007). Infant feeding in the modern world: Medicalization and the maternal body. Sociological Spectrum, 27(4), 405-438. doi:10.1080/02732170701335046

Weeks, C. (2010, July 11). Why aren't more women breastfeeding? The Globe and Mail. Retrieved from http://www.theglobeandmail.com

Wente, M. (2011, May 21). The tyranny of mother's milk; Women were made to feel that failing to nurse their babies was tantamount to child abuse. The Globe and Mail. Retrieved from http://www.theglobeandmail.com

When feeding baby, breast is best. (2010, January 10). Montreal Gazette. Retrieved from the Factiva database.

Wolf, J. (2011). Is breast best? Taking on the breastfeeding experts and he new high stakes of motherhood. New York: New York University Press.

Yadlon, S. (1997). Skinny woman and good mothers: The rhetoric of risk, control, and culpability in the knowledge about breast cancer. Feminist Studies, 23(3), 645-677. Retrieved from http://www.jstor.org/stable/3178391 